\title{
FÍSICA MODERNA E CONTEMPORÂNEA NO ENSINO BÁSICO: 0 CINTO DE SEGURANÇA COMO ALTERNATIVA PARA A ABORDAGEM TEÓRICA DO PRINCÍPIO DE EQUIVALÊNCIA DA RELATIVIDADE GERAL
}

\author{
Antônio Nunes de Oliveira ${ }^{1}$, Wilton Souza Sampaio ${ }^{1}$, Marcos Cirineu Aguiar Siqueira $^{1}$ \\ ${ }^{1}$ Instituto Federal de Educação, Ciência e Tecnologia do Ceará \\ <nunes.vieira@ifce.edu.br><wiltonsouzasampaio@gmail.com><mcirineu@gmail.com> \\ DOI: https://doi.org/10.21439/conexoes.v13i4.1859
}

\begin{abstract}
Resumo. O ano de 2019 marca os 100 anos de comprovação da Teoria da Relatividade Geral (TRG), a qual se deu mediante análise dos dados fotográficos coletados durante a observação do eclipse total do Sol, em Sobral-Ceará/Brasil e na Ilha do Príncipe-África, no dia 29 de maio de 1919. Visando contribuir com a inserção de tópicos de TRG no Ensino Básico (EB), Fundamental e Médio, este trabalho traz uma pesquisa bibliográfica e eletrônica buscando atualizar os leitores acerca do ensino de Física Moderna e Contemporânea (FMC) e, em seguida, apresenta uma proposta de vinculação entre os temas Princípio de Equivalência e a Educação para o Trânsito, a partir da qual se propõe, mediante a conscientização dos estudantes quanto à importância do uso do cinto de segurança, introduzir o Princípio de Equivalência nessa etapa do ensino. Os resultados apontam para um cenário em que praticamente inexistem abordagens com enfoque no referencial do carro e, como consequência, o uso do cinto de segurança tem sido justificado, quase que exclusivamente pela lei da inércia de Galileu-Newton, gerando erros conceituais na medida em que as pessoas tentam estender a explicação pautada no Princípio de Inércia para o observador no interior do veículo em desaceleração. Esse tipo de abordagem pode ocorrer a partir do $8^{\circ}$ ano do Ensino Fundamental, quando os alunos têm o primeiro contato com as leis de Newton e suas aplicações, momento que geralmente se explica o uso do cinto de segurança como necessidade para evitar a inércia dos corpos, negligenciando, geralmente, o ponto de vista de um observador interno ao veículo em colisão.
\end{abstract}

Palavras-chaves: Teoria da Relatividade Geral. Educação no Trânsito. Cinto de Segurança. Ensino Básico.

\begin{abstract}
The year of 2019 marks the 100 years of proof of the General Relativity Theory (GRT), which was accomplished by analyzing the photographic data collected during the observation of the total solar eclipse in Sobral-Ceará/Brasil and on the Island of Principe-África, on May 29, 1919. Aiming to contribute to the insertion of GRT topics in Basic Education (BE), Primary School and High School, this work brings a bibliographical and eletronical research that seeks to update the readers about the teaching of Modern and Contemporary Physics (MCP) and then presents a proposal of linkage between the themes Principle of Equivalence and Traffic Education, from which it is proposed, through the awareness of the students regarding the importance of using the seat belt, introduce the Principle of Equivalence in this stage of education. The results point to a scenario in which there are pratically none approaches with a focus on the car's referential, and as a consequence, the use of the seat belt has been justified, almost exclusively by the law of inertia of Galileo-Newton, generating conceptual errors to the extent that people try to extend the explanation set forth in the Principle of Inertia to the observer within the decelerating vehicle. This type of approach can occur from the 8th year of primary school, when the students have the first contact with Newton's laws and their applications, at which point the use of the seat belt is generally explained as a necessity to avoid inertia of bodies, neglecting, generally, an internal observer's point of view to the vehicle in collision.
\end{abstract}

Keywords: General Relativity Theory. Traffic Education. Safety Belt. Basic Education.

Conex. Ci. e Tecnol. Fortaleza/CE, v.13, n. 4, p. 7 - 17, dez. 2019 


\section{INTRODUÇÃO}

Há décadas vêm se intensificando as propostas que buscam justificar a importância do Ensino da Física Moderna e Contemporânea no Ensino Básico (EFMC no EB), verificar quais tópicos são os mais importantes e viáveis para transposição nesse nível de ensino, elaborar propostas metodológicas com vistas a favorecer tal inserção e produzir objetos de aprendizagem voltados ao ensino-aprendizagem de conceitos relacionados à FMC.

Nesse interim, houve atualizações dos livros didáticos, principais ferramentas disponíveis aos professores. Depois de analisar os livros didáticos do Programa Nacional do Livro Didático do Ensino Médio (PNLEM), Dominguini (2012) constatou que o conteúdo de FMC "se encontra em todos os livros didáticos do PNLEM, seja em forma de capítulo, ou unidade, ou textos dispersos ao longo da obra" (DOMINGUINI, 2012, p. 5). Além dos livros didáticos, as atualizações também estão presentes no currículo dos cursos de Licenciatura em Física, que passaram a contemplar disciplinas com tratamento específico de temas como Mecânica Quântica, Relatividade Restrita e Geral. Temas como estes têm ganhado tamanho destaque que inúmeras palestras 1 têm sido ministradas e até mesmo videoaulas 2 têm sido gravadas e disponibilizadas na internet, e estão disponíveis na web para o público em geral, consistindo em ferramentas úteis para aprendizagem, capacitação e atualização.

Diante de todo o destaque que tem ganhado a FMC, no que toca especialmente à sua inserção no $\mathrm{EB}$, a nossa proposta é introduzir alunos do EB à TRG por meio da Educação para o Trânsito (ET). A ET não tem tanto espaço no currículo escolar, sendo as normas de trânsito geralmente ensinadas às crianças e adolescentes na escola através de campanhas educativas, normalmente promovidas pelo Conselho Nacional de Trânsito

${ }^{1}$ Em Questão - Física Quântica, conversa com o professor Jose Abdalla Helayël Neto. Disponível em: <https://www.youtube.com/ watch?v=8BOi3Ze7UdA $>$ Acesso em: 07 de dez. 2019. UFRGSTV. Física quântica no seu dia-a-dia. Disponível em: <https:// www.youtube.com/watch?v=ZzrPYGY0tDg>Acesso em: $07 \mathrm{de} \mathrm{dez}$. 2019.

${ }^{2}$ Física Quântica, disciplina da UNIVESP, acesso em 07 de dez. 2019. Disponível em: <https: //www.youtube.com/watch? $\mathrm{v}=\mathrm{rpnNKvHbXPk \& list=}$

PLxI8Can9yAHdU3L15hRXuFOPhHvsdslLK> Acesso em: 07 de dez. 2019. Física Moderna, disciplina da UFF. Disponível em: <https://www.youtube.com/user/FisicaModernaUFF> Acesso em: 07 de dez. 2019. Curso de Relatividad General, Javier Garcia. Disponível em: <https://www.youtube.com/playlist?list= PLAnA8FVrB18DF03y6o-AIYPLK12F1IA25> Acesso em: $07 \mathrm{de}$ dez. 2019.
(CNT).

Sabe-se bem que muitos conteúdos e conceitos de Física podem ser ensinados usando o trânsito, como se vê em Moreira, Pereira e Martins (2017). Dentro deste contexto, a Lei da Inércia é geralmente ilustrada tomando como exemplo um objeto ou pessoa que segue o seu movimento para frente quando o veículo no qual ela está viajando freia. Contudo, defendemos que a Física Clássica não deve ser a única a ser explorada na abordagem desse fenômeno corriqueiro no trânsito. Aqui temos uma excelente oportunidade de apresentar aos alunos, o Princípio da Equivalência (PE) da TRG, introduzindo-o a partir dos mesmos acontecimentos usados para ilustrar a primeira lei de Newton, no entanto, abordando o fenômeno a partir do referencial do objeto ou pessoa que está dentro do veículo, ou seja, do referencial do próprio veículo.

Os acidentes de trânsito têm causado muitas perdas, desde sequelas físicas e emocionais em quem se envolve em algum acidente, até mesmo a morte. Os números do ano de 2018 mostram que acidentes de trânsito constituem a principal causa de internações no estado do Espirito Santc ${ }^{3}$, isso se repete na cidade de João Pessoa ${ }^{4}$, no estado da Paraíba; esses dados parecem retratar a realidade aproximada de muitos outros lugares do Brasil. Mortes e sequelas graves poderiam ser evitadas a partir do uso do cinto de segurança, deste modo o objetivo deste trabalho, além sugerir uma forma de se introduzir um tópico da TRG no EB (âmbito geral), é conscientizar crianças e jovens acerca da importância do uso desse equipamento tão simples, mas que pode salvar vidas. Pensamos ainda, num âmbito mais específico, uma vez que os estudantes (crianças ou jovens) compreendam a importância do uso do cinto de segurança, sabendo explicá-la sob a perspectiva dos diferentes referenciais envolvidos, eles irão influenciar os adultos e se tornarão agentes educadores.

\section{METODOLOGIA}

Para a realização deste trabalho, primeiramente investigou-se em meios eletrônicos, dados relativos ao uso do cinto de segurança e, posteriormente, usando li-

\footnotetext{
${ }^{3}$ Acidentes de Trânsito são a Principal Causa de Internações em Hospitais do ES. Disponível em: https://g1.globo.com/es/espiritosanto/noticia/acidentes-de-transito-sao-a-principal-causa-deinternacoes-em-hospitais-do-es.ghtml. Acesso em: $22 \mathrm{de} \mathrm{fev.}$ 2019.

${ }^{4}$ Acidentes de Trânsito Lideram Entradas no Hospital de Trauma de João pessoa. Disponível em:https://paraibaonline.com.br/2018/04/acidentes-de-transitolideram-entradas-no-hospital-de-trauma-de-joao-pessoa/. Acesso em: 22 de fev. 2019
} 
vros de Física, buscou-se fundamentar uma explicação centrada nos passageiros e embasada no Princípio de Equivalência para justificar a necessidade e importância do uso do cinto de segurança em veículos automotores. Foi feito, então, um levantamento de artigos científicos e periódicos eletrônicos que apresentassem propostas metodológicas alternativas para a inserção das temáticas referentes à TRR e à TRG no Ensino Básico, tendo como foco a apreensão das principais dificuldades e limitações práticas nos processos de ensinoaprendizagem.

\section{RESULTADOS E DISCUSSÕES}

\subsection{A PESQUISA BIBLIOGRÁFICA E ELETRÔNICA}

A seguir apresentamos alguns dos principais estudos referentes à vertente EFMC no EB, em especial, aqueles que tratam do Ensino da Teoria da Relatividade Geral no Ensino Básico (ETRG no EB), a partir dos quais é possível constatar que tipos de abordagens favorecem a inclusão da TRG nos ensinos Fundamental e Médio.

\section{Física Moderna e Contemporânea no Ensino Básico}

Antes de apresentarmos os resultados de pesquisas sobre o ETRG no EB vejamos alguns pontos importantes sobre o EFMC no EB. No Quadro 1 estão listadas as principais justificativas encontradas em Silva, Arenghi e Lino (2013) e em Ostermann e Moreira (2000), para a inserção da Física Moderna e Contemporânea (FMC) no Ensino Médio (EM).

Os resultados do Quadro 1 referem-se à análise de trabalhos acadêmicos publicados nos últimos 10 (dez) anos anteriores à publicação de Silva, Arenghi e Lino (2013) juntamente com os dados do trabalho de revisão bibliográfica sobre a área de pesquisa FMC no EM dos autores Ostermann e Moreira (2000).

Outro ponto importante ao tratarmos do EFMC no EB é quais tópicos são viáveis para transposição neste nível de ensino. Para Terrazzan (1992), a seleção de conteúdos de FMC para o EB deve levar em consideração o "equilíbrio entre as necessidades que a própria ciência física impõe para que haja consistência na apresentação dos tópicos e para que se privilegie leis gerais e conceitos fundamentais" (TERRAZZAN, 1992, p. 211). Para o autor, "deve-se refletir sobre as possibilidades de desenvolvimento desses tópicos com poucas exigências de cálculos matemáticos" (TERRAZZAN 1992, p. 211). No Quadro 2 estão listados os principais tópicos relacionados à FMC indicados para abordagem no EB.

Os dados do Quadro 2 surgiram a partir de uma análise de trabalhos publicados na área de pesquisa FMC no EB, entre 2000 e 2017. Dentre tais trabalhos podemos destacar os de Cruz e Guerra (2009) e Aringhieri e Silva (2017) que tratam da inserção da FMC no Ensino Fundamental, e os trabalhos de Silva, Arenghi e Lino (2013), Ferreira e Silva (2007), Guerra, Braga e Reis (2007), direcionados ao Ensino Médio.

Finalmente, apresentadas as justificativas para a inserção de tópicos de FMC no EB e destacados os temas apontados pelas pesquisas nessa área, que está cada vez mais em ascensão, é importante, segundo Terrazzan (1992), que vejamos a questão das metodologias a serem empregadas. A seguir, apresentamos algumas dessas metodologias.

\section{Ensino de Relatividade Geral no Ensino Básico}

Segundo Ferreira e Silva (2007), uma proposta que vise a inclusão da Teoria da Relatividade Geral no EM, a princípio, é muito audaciosa, no entanto, devemos considerar que ela é imprescindível ao estudante, permitindo a ele compreender a evolução do pensamento científico e atualizar-se a respeito dele. Em especial, a Teoria da Relatividade Geral possibilitará ao estudante compreender a transição da gravitação newtoniana, na qual aparece a força gravitacional como justificativa para o movimento dos astros, para a gravitação einsteiniana, onde os movimentos são explicados tomando como referência o comportamento do próprio espaço que, curvado pela presença de matéria, diz a esta como ela deve se mover.

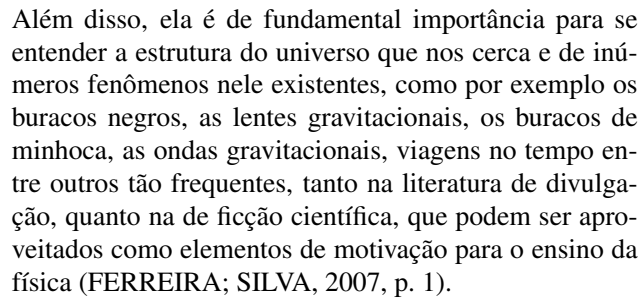
entender a estrutura do universo que nos cerca e de inúmeros fenômenos nele existentes, como por exemplo os buracos negros, as lentes gravitacionais, os buracos de minhoca, as ondas gravitacionais, viagens no tempo entre outros tão frequentes, tanto na literatura de divulgação, quanto na de ficção científica, que podem ser aproveitados como elementos de motivação para o ensino da física (FERREIRA; SILVA] 2007. p. 1).

Ferreira e Silva (2007) montaram, em formato de artigo, um material paradidático, e o sugerem como proposta metodológica para inserção dos tópicos PE e a Curvatura do Espaço-Tempo no Ensino Básico. Nesse material faz-se uma excelente transposição didática através do uso de textos explicativos, figuras ilustrativas, e exemplos relacionados a tais tópicos. Esses autores defendem ainda que, para os estudantes entenderem o universo (sua concepção atual), eles precisam 
Quadro 1: Principais justificativas para o ensino de Física Moderna e Contemporânea no Ensino Médio.

\begin{tabular}{l} 
JUSTIFICATIVAS PARA INSERÇÃO DA FMC NO EM \\
\hline A inserção de FMC no EM é importante para a compreensão das tecnologias da atualidade: \\
- Ela possui múltiplas e evidentes consequências tecnológicas \\
- Vivemos num mundo tecnológico e compreender o nosso entorno envolve compreender princípios \\
relacionados a FMC. \\
\hline A necessidade de atualização curricular do Ensino Médio: \\
- Os currículos escolares atuais estão centrados quase que exclusivamente na física produzida até \\
meados do século XIX, negligenciando a ciência produzida desde então \\
- Atualizar o currículo escolar inserindo tópicos de FMC no EB pode servir para renovar o ensino, \\
uma vez que tais tópicos têm o potencial de despertar o interesse das crianças pelas ciências \\
- É função da escola incluir em seu currículo assuntos relevantes para a formação de um cidadão \\
esclarecido sobre o que o cerca, apto a opinar sobre pontos que envolvem o seu destino e neste contexto \\
a FMC mostra-se essencial \\
- Conteúdos como Relatividade, Astronomia e Partículas Elementares estão entre os que mais despertam \\
o interesse dos jovens na escolha pela carreira de físico. \\
A Física Moderna e Contemporânea representou uma mudança de paradigma da Física e essa \\
noção de desenvolvimento das ciências se faz necessária no EM: \\
- A aprendizagem de conteúdo de FMC pode contribuir com a superação de barreiras etimológicas \\
fundamentais para o conhecimento sobre a natureza \\
- A FMC pode contribuir com a imagem mais correta da ciência e da natureza do trabalho científico. \\
\hline A FMC serve como subsídio à compreensão e crítica das questões atuais que envolvem ciência, \\
tecnologia, sociedade e ambiente: \\
- A FMC torna-se instigante à medida que possibilita aos estudantes compreenderem as falas atuais de \\
cientistas, notícias que estão constantemente nas mídias com relatos sobre seus experimentos e \\
perspectivas para o futuro.
\end{tabular}

Quadro 2: Tópicos de Física Moderna e Contemporânea no Ensino Básico.

\begin{tabular}{|c|c|c|}
\hline FMC NO EB & $\begin{array}{c}\text { TÓPICOS NO ENSINO } \\
\text { FUNDAMENTAL }\end{array}$ & $\begin{array}{c}\text { TÓPICOS NO ENSINO } \\
\text { MÉDIO }\end{array}$ \\
\hline $\begin{array}{c}\text { TEORIA } \\
\text { QUÂNTICA }\end{array}$ & $\begin{array}{l}\text { - Energia;- Radiação; } \\
\text { - Fissão nuclear; } \\
\text { - Armas Químicas e Biológicas; } \\
\text { - Efeito fotoelétrico. }\end{array}$ & $\begin{array}{l}\text { - Efeito fotoelétrico; } \\
\text { - Laser; } \\
\text { - Emissão de corpo negro; } \\
\text { - O princípio de Incerteza } \\
\text { de Heisenberg; } \\
\text { - Espectros atômicos; } \\
\text { - Modelos atômicos; } \\
\text { - Dualidade onda partícula. }\end{array}$ \\
\hline $\begin{array}{l}\text { TEORIA DA } \\
\text { RELATIVIDADE } \\
\text { RESTRITA }\end{array}$ & $\begin{array}{l}\text { - Movimento Relativo; } \\
\text { - A velocidade da Luz; } \\
\text { - Paradoxo dos gêmeos. }\end{array}$ & $\begin{array}{l}\text { - Dilatação dos intervalos de tempo; } \\
\text { - Contração de comprimentos; } \\
\text { - Efeito Doppler Relativístico; } \\
\text { - A relação massa-energia. }\end{array}$ \\
\hline $\begin{array}{l}\text { TEORIA DA } \\
\text { RELATIVIDADE } \\
\text { GERAL }\end{array}$ & $\begin{array}{l}\text { - O princípio de Equivalência; } \\
\text { - Evolução dos conceitos tempo e espaço; } \\
\text { - Geometria do espaço-tempo. }\end{array}$ & $\begin{array}{l}\text { - Princípio da Equivalência; } \\
\text { - Geometrização da Gravitação; } \\
\text { - Buracos negros; } \\
\text { - Buracos de Minhoca; } \\
\text { - Ondas gravitacionais; } \\
\text { - Viagens no tempo; } \\
\text { - Modelos cosmológicos. } \\
\text { - Viagens no tempo; } \\
\text { - Modelos cosmológicos. }\end{array}$ \\
\hline
\end{tabular}


abandonar a visão de um espaço plano alimentada pela Física newtoniana e assimilar o espaço como sendo algo maleável, que sofre alterações devido à presença de matéria.

Eles sugerem ainda uma produção de textos destinados a professores do nível médio que apresente de forma simples conteúdos como: buracos negros, buracos de minhoca, ondas gravitacionais, viagens no tempo e modelos cosmológicos, capacitando-os "a responder perguntas sobre estes temas, que certamente surgiram como curiosidade dos estudantes após o estudo das bases da TRG" (FERREIRA; SILVA, 2007, p. 9). No decurso das leituras que subsidiaram este trabalho, buscou-se um alinhamento com tal proposta no que toca particularmente à sua grande capilaridade dentro corpo estudantil, ou seja, as ideias tornam-se convincentes tanto para os alunos mais aplicados, quanto para aqueles que têm mais dificuldade com a Física.

Na Figura 19) (FERREIRA; SILVA, 2007) passam a impressão de geometria euclidiana (menor distância entre dois pontos sendo uma reta), já a Figura 1 b) objetiva, de forma bem simplista, passar a impressão de um espaço análogo ao da TRG (espaço não euclidiano), "curvado pela presença de matéria".

A mudança de concepção a respeito do espaço sempre vem acompanhada de profundas reflexões filosóficas, sendo o conhecimento comum de determinada época um grande influenciador até mesmo das produções artísticas. Nesta perspectiva, Guerra, Braga e Reis (2007) trazem uma proposta para o ensino da Teoria da Relatividade (Restrita e Geral) na primeira série do Ensino Médio, dentro do programa de Mecânica, construída a partir de uma abordagem histórico-filosófica da ciência. Para esses autores, "a relação entre a Física com outras produções culturais constitui-se no viés privilegiado para se trabalhar com os adolescentes as questões científicas respondidas pelos trabalhos de Albert Einstein", (GUERRA; BRAGA; REIS, 2007) p. 575).

Ao abordarem conceitos como referencial inercial, posição, deslocamento, velocidade e aceleração, enfatizando as transformações de Galileu e levando em consideração a construção histórica desses conceitos, (GUERRA; BRAGA; REIS, 2007) fazem uso do filme O Nome da Rosa dirigido por Jean-Jacques Annaud (1986). A exposição do filme motivou um debate entre os alunos e o professor em torno do nascimento da ciência moderna, em especial, da Teoria da Relatividade Restrita. Para estes autores o enfoque dado teria sido mais rico mediante uma abordagem interdisciplinar envolvendo os professores de Física e História, entretanto, a organização dos tempos regulares das disciplinas não colaborou com a implementação de uma proposta desse tipo.

Em um outro momento de sua pesquisa, (GUERRA; BRAGA; REIS, 2007) fazem uso das obras de arte como: Entrada em Jerusalém de Duccio de Sienna (1308/11); A Madona do Chanceler Rolin de Jan Van Eyck (1435); Piquenique sobre a relva de Édouard Manet (1863) e, As Moças de Avignon de Pablo Picasso (1907). A exposição dessas obras possibilitou aos envolvidos discutirem e percebem a evolução das expressões dos pintores para o espaço, em suas obras de arte, de acordo com o período de cada uma. O Quadro3 3 relaciona as obras citadas e as concepções de espaço da época.

As características associadas ao espaço que foram destacadas no Quadro 3 apontam para uma possível interferência do quadro científico da época com as expressões artísticas manifestadas nas pinturas. A pesquisa de Guerra, Braga e Reis (2007) aponta ainda como possibilidade para despertar nos alunos o interesse por temas de FMC e lhes mostrar a aproximação desta com assuntos relacionados à cultura, tecnologia e sociedade, estimular os alunos a estudos dirigidos e propor apresentações valorizando sua criatividade e trabalho em grupo.

Esta perspectiva, mais inclinada à historicidade, também norteou as leituras que antecederam a redação deste trabalho, sobretudo enquanto critério de eficiência nas transposições e, apesar de não surgir de forma explícita na proposta final, mostrou-se de suma importância no entendimento do que é mais assimilável aos alunos na proposta de um dado método de ensino.

Buscando contribuir com o ETRG, Medeiros e Medeiros (2005) trazem como proposta para o ensino do $\mathrm{PE}$, usar brinquedos para ilustrar de forma lúdica tal princípio, atraindo os estudantes e gerando um clima de alegria ao aprender. Eles citam duas experiências do próprio Einstein com os brinquedos didáticos em Física. O primeiro deles é a bússola que o cientista teria ganhado em sua infância, a qual gerou nele a sensação de mistério e o conflito cognitivo. O segundo se referia a um quebra-cabeças (elevador de brinquedo), derivado de um antigo brinquedo de crianças, o qual foi presenteado a Einstein por Eric Rogers, em seu aniversário de 70 anos. Segundo esses autores, assuntos científicos mais complexos como, por exemplo, o Princípio de Equivalência da Relatividade Geral tem ganhado mais atenção dos pesquisadores da área de EFMC uma vez que estes passaram a buscar novas formas mais eficientes de realçarem as questões conceituais e imagéticas que não estejam focadas em aspectos formais da teoria.

A Figura 2 ilustra brinquedos que podem ser utili- 
Figura 1: 1a) Ser bidimensional na folha de papel, seu universo; 1b) folha amassada com o ser bidimensional que vive nela.

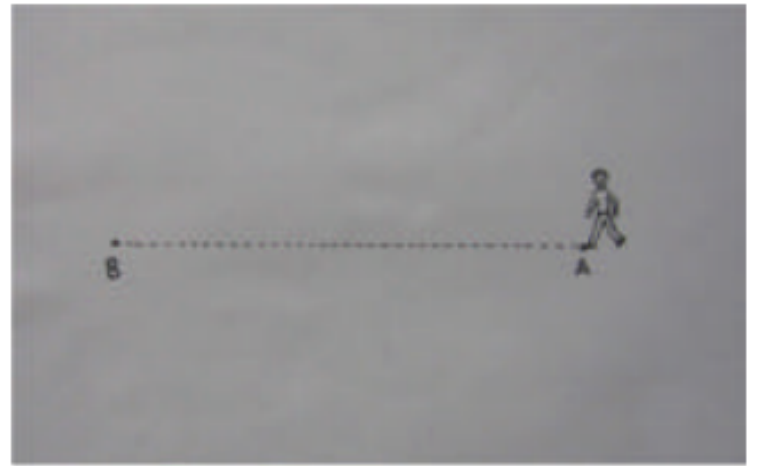

a)

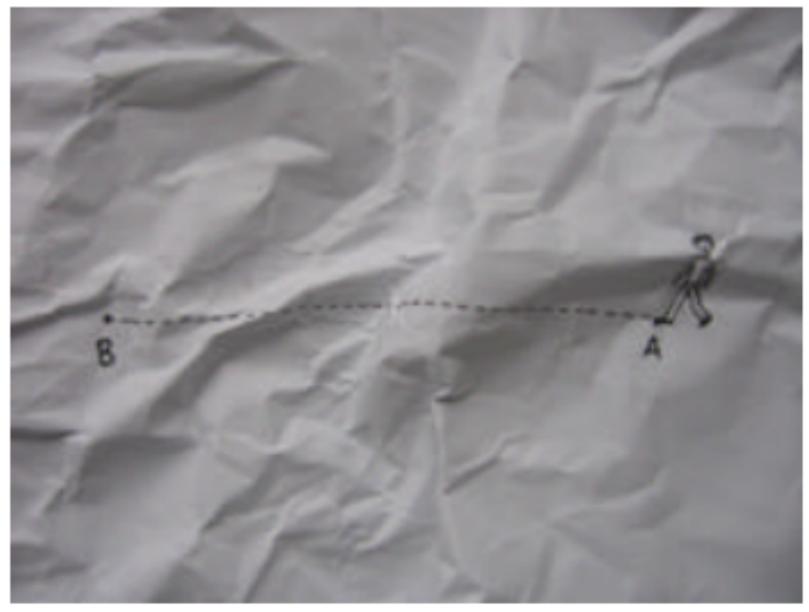

b)

Fonte: (FERREIRA; SILVA 2007 p. 7).

Quadro 3: Relação entre obras de artes e as concepções de espaço em determinados períodos da história da arte/ciência.

\begin{tabular}{|c|c|}
\hline OBRA DE ARTE & CARACTERÍSTICAS DO ESPAÇO \\
\hline $\begin{array}{c}\text { Entrada em Jerusalém } \\
\text { Duccio de Sienna }(1308 / 11)\end{array}$ & $\begin{array}{l}\text { Espaço hierarquizado e heterogêneo (período medieval). O céu é uniforme } \\
\text { e monótono, sendo representado no quadro por cores douradas (ao céu } \\
\text { estavam reservados o movimento perpétuo e a imutabilidade). A Terra, por } \\
\text { sua vez compunha diversidades. O tamanho das pessoas retratadas } \\
\text { corresponde à posição social que elas ocupam naquele contexto. }\end{array}$ \\
\hline $\begin{array}{l}\text { A Madona do Chanceler Rolin } \\
\text { Jan Van Eyck (1435) }\end{array}$ & $\begin{array}{l}\text { Céu e Terra formam um todo (o céu não é mais local da permanência, como } \\
\text { a Terra ele apresenta fenômenos efêmeros). O tamanho atribuído às pessoas, } \\
\text { às árvores, às montanhas é calculado pela técnica da pintura em perspectiva. } \\
\text { O espaço não tem mais limite claro, o infinito pode ali ser contemplado } \\
\text { (representação espacial típica da mecânica newtoniana - espaço homogêneo } \\
\text { e isotrópico, a presença de objetos não o altera). }\end{array}$ \\
\hline $\begin{array}{l}\text { Piquenique sobre a relva } \\
\text { Édouard Manet (1863) }\end{array}$ & $\begin{array}{l}\text { O espaço não mais é tratado como homogêneo e as regras da perspectiva } \\
\text { clássica não estão plenamente respeitadas. }\end{array}$ \\
\hline $\begin{array}{l}\text { As Moças de Avignon } \\
\text { Pablo Picasso (1907) }\end{array}$ & $\begin{array}{l}\text { Espaço distorcido e as regras da perspectiva não mais se fazem presentes. } \\
\text { Não há o espaço fechado e hierarquizado do medievo, mas também não } \\
\text { se encontra o espaço homogêneo e isotrópico de Galileu-Newton. }\end{array}$ \\
\hline
\end{tabular}

zados durante o ensino da TRG para ilustrar o PE. Com exceção do primeiro, os demais brinquedos são bastante simples de serem replicados, além disso, os materiais usados em sua construção possuem baixo custo, podendo ainda serem adaptados conforme realidade e criatividade dos envolvidos, o que certamente os tornam viáveis de uso nas escolas brasileiras.

Rodríguez, Reyes e Ortiz (2014) propõem a construção do brinquedo de Einstein como uma metodologia para revisar conceitos de Mecânica Clássica e, ao mesmo tempo, introduzir o Princípio de Equivalência. Esses autores propõem utilizar o brinquedo mediante uma abordagem investigativa onde os estudantes são instigados a pensar buscando soluções as questões levantadas pelo professor. Um outro fator que diferencia o trabalho de Rodríguez, Reyes e Ortiz (2014) do trabalho de Medeiros e Medeiros (2005) é a utilização do programa IMAGI FIJI 1,46, que permite calcular a velocidade dos componentes do brinquedo além de inferir valores para o tempo de queda. 
Figura 2: 2a) Elevador de brinquedo presenteado a Einstein por Eric Rogers; 2b) Elevador com ressonador; 2c) Elevador com elástico; 2d) Elevador com água.

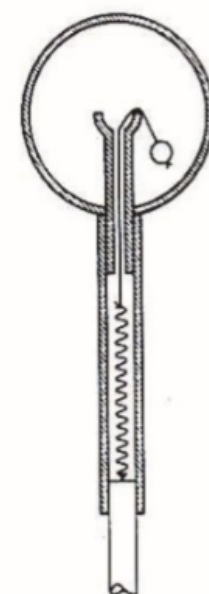

a)

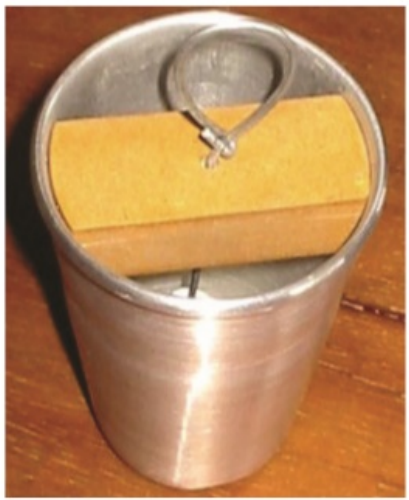

b)

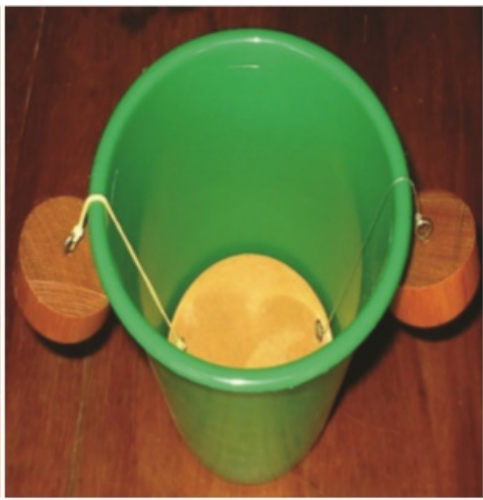

c)

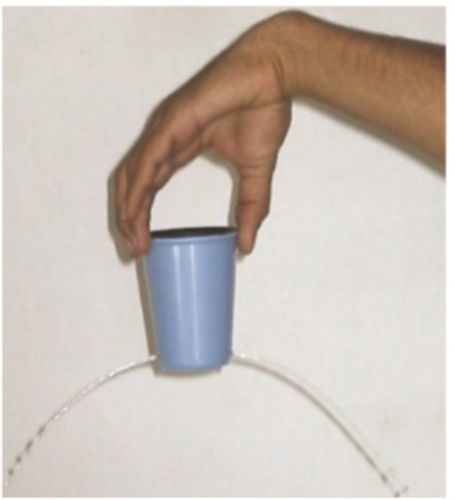

d)

Fonte: (MEDEIROS; MEDEIROS |2005 p. 311-312).

A Figura 3 ilustra uma representação do brinquedo de Einstein feita por Rodríguez, Reyes e Ibánez (2014). Pesos não fixados na parte interior da caixa, de modo a evitar que ela gire durante a queda. Na figura estão ilustradas as forças $W$ (peso), $N$ (normal) e $T$ (tração=força elástica) que atuam sobre a massa pendurada quando esta se encontra em condições normais (repouso ou movimento retilíneo em linha reta).

Figura 3: Protótipo didático do brinquedo de Einstein.

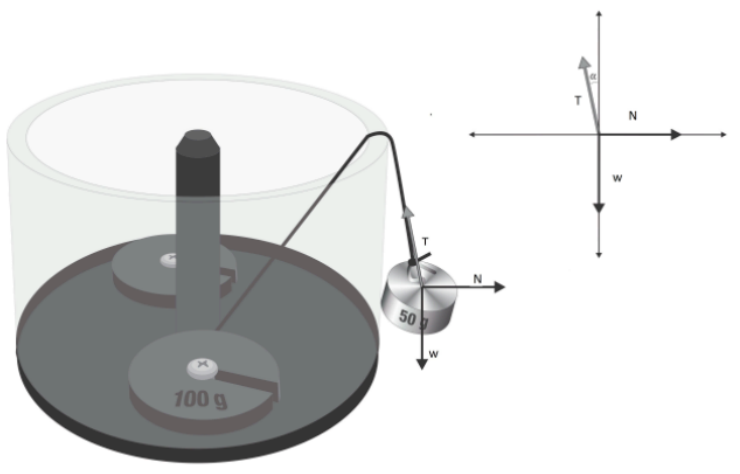

Fonte: (RODRÍGUEZ; REYES; ORTIZ 2014 p. 4509-3).

Uma vez que o protótipo da Figura 3 seja posto em queda livre com aceleração vertical igual a $\vec{q}$, pelo Princípio de Equivalência, podemos pensar no referencial do brinquedo como um referencial inercial no qual a massa de 50 g estará sujeita a uma força vertical igual, em módulo, ao seu peso, mas com sentido contrário a ele. Esta força anula o peso natural do corpo (peso da massa $m$ quando ela está em repouso, sujeita ao campo gravitacional terrestre $\vec{q}$ ) e, desta forma, a força elástica $T$ obriga a massa a entrar na caixa.

Aringhieri e Silva (2017) trazem uma proposta para abordar de forma lúdica temas da FMC em escolas do Ensino Fundamental, também usando experimentos com a mesma função pedagógica dos brinquedos de (MEDEIROS; MEDEIROS, 2005), além de utilizar-se do Teatro de Fantoches. Tal abordagem visou oferecer aos alunos conhecimentos que favorecessem uma melhor percepção, análise crítica e contexto do mundo ao seu redor. Os experimentos realizados no trabalho de Aringhieri e Silva (2017) são voltados a explorar a compreensão dos temas propostos, os quais envolvem: Disco de Newton, a Luminescência, o Efeito Fotoelétrico, Big Bang e a Deformação do espaço-tempo.

A Figura 4 é uma ilustração da expansão do universo na teoria do Big Bang. Ao inflar o balão o espaço sofre expansão e os objetos presentes neles, em consequência, são afastados uns dos outros, não existe um ponto privilegiado no balão indicando, por analogia, que o universo não possui centro e expande-se para todas as direções. Por outro lado, se este mesmo balão for muito inflado, tornando-se muito grande, em relação a um observador postado na sua superfície, a sua curvatura pareceria plana. Na prática, este fato representa uma consequência do final do período inflacionário, no qual o Universo experimentou uma taxa de expansão 
muito acelerada, a partir da qual se explica o problema da planura.

Figura 4: Uma ilustração da expansão do universo.
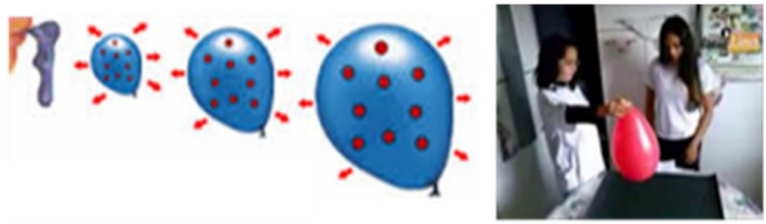

Fonte: ARINGHIERI; SILVA 2017 p. 6).

Outra ilustração presente no trabalho de Aringhieri e Silva (2017), representada na Figura 5, representa a etapa da execução experimental realizada pelos alunos sobre o fenômeno da deformação no tecido do espaçotempo. Particularmente no que diz respeito a essa proposta, chamou a atenção a grande eloquência da exposição feita inteiramente com materiais de baixo custo, fato que também serviu como elemento deste trabalho.

Figura 5: Execução da atividade experimental com ajuda dos alunos sobre a deformação espaço/tempo.

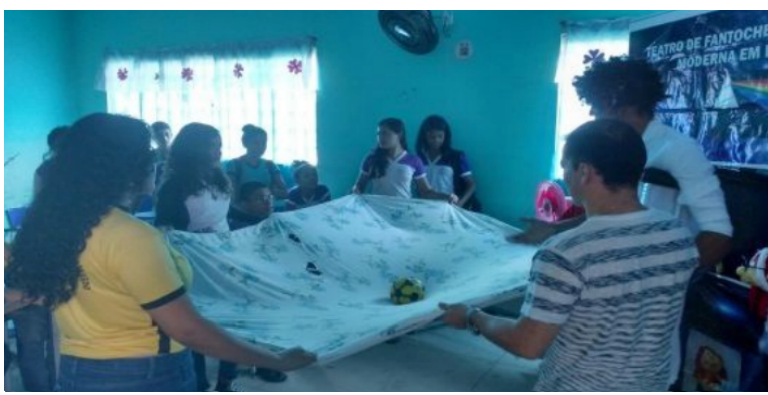

Fonte: ARINGHIERI; SILVA 2017 p. 6).

\section{Educação para o trânsito}

É fato constatado, que o uso do cinto de segurança é um elemento essencial para passageiros e condutores de veículos automotores, entretanto, estatísticas aprontam para a negligência 5 do uso desse equipamento, o que tem acarretado inúmeras mortes no trânsito, apesar do investimento na conscientização das pessoas. Pensando em contribuir com a solução do problema, fica sugerido neste trabalho, atrelar os temas O Princípio de Equivalência e o Uso do Cinto de Segurança, trazendo-os

${ }^{5}$ Cinto de segurança no transporte rodoviário: uma preocupação. ONSV. Disponível em: http://www.onsv.org.br/cinto-de-segurancano-transporte-rodoviario-umapreocupacao/. Acesso em, 04 nov. 2018. simultaneamente para sala de aula através de uma discussão física acerca da explicação da importância do cinto de segurança, levando em conta o ponto de vista do observador no interior do veículo (observador não inercial).

O Código de Trânsito Brasileiro (CTB) traz orientações a respeito de como se portar no trânsito e, além disso, incentiva a divulgação de suas normas através dos meios de comunicação mais acessíveis como TV, rádio e até mesmo a própria escola. A versão mais atual do CTB, instituído através da sanção da Lei no 9.503, de 23 de setembro de 1997, traz em seu texto um capítulo com seis artigos dedicado exclusivamente à ET. Segundo o artigo 76 desse capítulo:

\section{Art. $76^{\circ}$. A educação para o trânsito será promovida na pré-escola e nas escolas de $1^{\circ}, 2^{\circ}$ e $3^{\circ}$ graus, por meio de planejamento e ações coordenadas entre órgãos e en- tidades dos Sistema Nacional de Trânsito e de Educação, da União, dos Estados, do Distrito Federal e dos Municí- pios, nas respectivas áreas de atuação (BRASIL 1997).}

A citação acima institui que a Educação no Trânsito deve estar presente na Educação Básica, desde o Ensino Fundamental até o Médio e serviu como baliza para a proposta final. As ações a serem realizadas em favor dessa causa não devem ser aleatórias ou de improviso, mas organizadas e planejadas previamente. $\mathrm{O}$ inciso primeiro do parágrafo único do Art. $76^{\circ}$ diz que o Ministério da Educação e do Desporto (MEC), aliado ao Conselho Nacional de Trânsito (CONTRAN) e ao Conselho de Reitores das Universidades Brasileiras (CRUB), promoverá a adoção, em todos os níveis de ensino, de um currículo interdisciplinar com conteúdo programático sobre segurança de trânsito. Diante dos reclames da lei, é viável a apresentação de uma proposta que envolva segurança no trânsito e tópicos de TRG. Tal tipo de proposta satisfaz à exigência de um "currículo interdisciplinar".

\subsection{UMA PROPOSTA PARA A ABORDAGEM TEÓ- RICA DO PRINCÍPIO DE EQUIVALÊNCIA}

No Ensino Básico é praticamente unânime justificar a utilização do cinto de segurança via o Princípio de Inércia. Até aqui não há nada de errado que se possa questionar, o problema ocorre quando os estudantes, por não dominarem assuntos relacionados à dinâmica em referenciais não inerciais, tentam estender sua explicação para observadores internos aos veículos, que, por sofrerem desaceleração durante o choque constituem, em essência, referenciais não inerciais. Vejamos as possíveis explicações que podem ser utilizadas para justificar o uso do cinto de segurança em veículos automotores: 
a) Observador externo ao veículo;

Consideremos os referenciais $S$ e $S^{\prime}$, com afastando-se de $S$ a uma velocidade constante $\vec{u} \hat{e}$, onde ê é um vetor unitário que aponta para o sentido positivo do $O X \equiv O X^{\prime}$, Figura 6 .

Figura 6: A Inércia dos corpos como justificativa para o uso do cinto de segurança em veículos automotores.

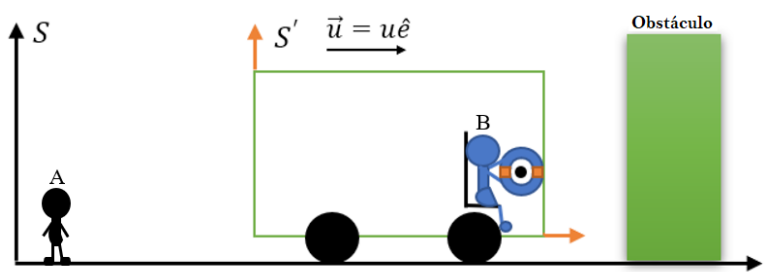

Olhando a Figura 6 percebemos que o observador $\mathrm{B}$ segue em movimento retilíneo e uniforme na horizontal, do ponto de vista do observador A. Na perspectiva do observador A, após o choque do veículo com o obstáculo, o observador B segue, por inércia, uma trajetória retilínea, chocando-se contra o para-brisa do veículo. O cinto de segurança, uma vez ativado, atua exercendo uma força sobre o motorista, desacelerandoo igualmente ao veículo, logo, ele impede que o portador saia do interior do veículo, garantindo maior integridade física a ele.

b) Observador interno ao veículo;

O Princípio de Inércia não justifica a obrigatoriedade do uso do cinto de segurança na perspectiva do observador B, uma vez que, para esse observador, ele está parado em relação ao carro e logo, por inércia ele deveria permanecer em repouso, mas não é isso que ocorre: o observador B, sob seu ponto de vista, é lançado contra o para-brisa do veículo. O professor pode explicar esse fato observando que o carro em desaceleração é um referencial acelerado e corpos situados nesse tipo de referencial estão sujeitos às chamadas forças de inércia. São exemplos de força de inércia: a força centrífuga que age sobre a sua roupa quando esta está na máquina durante o processo de secagem; a força de Coriolis e, finalmente, a força de Einstein (força que atua sobre um corpo quando este está em desaceleração durante um movimento em linha reta).

A fim de vincularmos os temas o uso do cinto de segurança e o PE, sugerimos que a força de Einstein seja apresentada como uma força de gravidade local, que é inserida quando se troca, usando o PE, o referencial acelerado do carro por um referencial inercial equivalente onde, além do peso inicial do corpo, é acrescentado um peso extra cuja orientação é contrária à desace- leração do veículo e cujo módulo corresponde ao produto da massa do corpo pelo módulo de sua aceleração. A introdução de tal conceito nesse contexto particular permitiria ao estudante ser capaz de explicar satisfatoriamente os eventos que acontecem no interior de um veículo em colisão sem ter que apelar para um referencial externo ao veículo.

Figura 7: Forças atuantes sobre o motorista: (a) perspectiva do observador A; (b) Perspectiva do observador B.

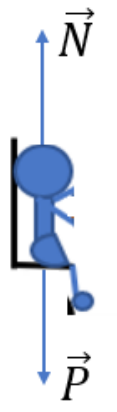

(a)

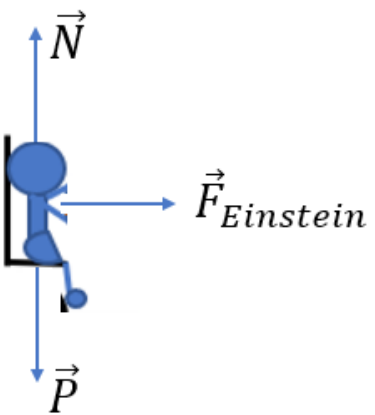

(b)
A força de Einstein fica definida operacionalmente como

$$
F_{\text {Einstein }}=-m a
$$

onde $m$ é a massa do corpo e $a$ é o módulo da aceleração do veículo. O sinal de menos na equação deve-se ao fato de a força atuar contrariamente à aceleração adquirida pelo veículo.

\subsection{UMA ANÁLISE PRÁTICA DA QUESTÃO}

De acordo com a Agência Nacional de Transportes Terrestres (ANTT) ${ }^{6}$ em média, de cada 10 passageiros de ônibus intermunicipais no Brasil, só 4 usam habitualmente o cinto de segurança, sendo que, o uso correto do cinto reduz substancialmente a gravidade dos traumas em caso de acidente. Durante uma colisão a 60 $\mathrm{km} / \mathrm{h}$, o corpo de um passageiro é naturalmente projetado para frente e para cima com uma força até 15 vezes maior que o seu próprio peso. $\mathrm{Na}$ ausência do cinto, ele não só corre o risco de sofrer fraturas graves ao bater a cabeça no teto, como pode também atingir a pessoa que ocupa o assento da frente, tudo isso em frações de segundo.

\footnotetext{
${ }^{6}$ Flagrante Indica que Passageiros não Utilizam Cinto de Segurança em Linhas Intermunicipais. Jornal da EPTV. $1^{\mathrm{a}}$ ed. Campinas-Piracicaba. Disponível em: https://globoplay.globo.com/v/7795264/programa/. Acesso em: 13/12/2019.
} 
Numa colisão a $65 \mathrm{~km} / \mathrm{h}$ o veículo desacelera até a velocidade $0 \mathrm{~km} / \mathrm{h}$ em cerca de 1 segundo, ou seja, o módulo da aceleração atuante sobre o veículo é de aproximadamente $18 \mathrm{~m} / \mathrm{s}^{2}$. A força de Einstein, ou seja, o peso extra, que irá atuar sobre um indivíduo com $70 \mathrm{Kg}$ (adulto comum de altura mediana), quando submetido a essa aceleração, é de aproximadamente 1260 N. Esse valor representa quase o dobro do peso do mesmo adulto na Terra, mas ainda parece pequeno quando comparado aos dados anteriores. Essa divergência ocorre devido ao fato de que, quando as partes do corpo colidem com as partes do veículo, existe uma força devida ao impulso que é muito superior à força de Einstein. O mesmo ocorre, por exemplo, quando uma bola colide com o chão: a força que rebate a bola é muito superior ao peso dela.

A pesquisa realizada apontou ainda, entre outras coisas $^{5}$ : que $38 \%$ dos passageiros no banco de trás não usam o cinto; que $98 \%$ de passageiros de ônibus e vans ignoram esse elemento; que o cinto de segurança reduz em $70 \%$ os riscos de lesões, em $40 \%$ os riscos de mortes dos passageiros, e que um em cada quatro pais não coloca o cinto de segurança nas crianças quando a distância a ser percorrida é muito curta, ignorando os riscos. Dentro desde contexto, o ensino do Princípio de Equivalência aliado ao uso do cinto de segurança constitui ao mesmo tempo uma importante estratégia para o ensino de tópicos Relatividade Geral no Ensino Básico, Fundamental e Médio, e uma oportunidade de educar os condutores a partir da educação escolar dos passageiros.

\section{CONCLUSÕES}

As justificativas apresentadas por Silva, Arenghi e Lino (2013) para a inserção da FMC no EM continuam atuais e podem ser estendidas para as duas séries finais do Ensino Fundamental, quando os alunos têm seu primeiro contato com alguns dos conteúdos de Física. É preciso pensar em quais conteúdos são pertinentes para tal inserção no Ensino Fundamental e viabilizála através de propostas como as de Ferreira e Silva (2007), Medeiros e Medeiros (2005), Guerra, Braga e Reis (2007), Aringhieri e Silva (2017).

Vale destacar que houve poucos avanços, nos últimos anos, no sentido da implementação de tópicos de FMC no EB, em parte devido ao deficitário currículo escolar desse nível, que ainda negligencia a importância de tópicos de FMC na formação básica dos estudantes, isso é claro, aliado ao fato de que, de um modo geral, os professores não se sentem totalmente à vontade para abordar assuntos relacionados à FMC, seja pela centra- lidade dos conteúdos guiada pelo Exame Nacional do Ensino Médio ou por deficiências em sua própria formação. É preciso, urgentemente, demandarmos esforços para produzir respostas que reforcem a consciência da necessidade e viabilidade da FMC no EB, e que ofereçam aos professores metodologias praticáveis em seus contextos sociais, por exemplo, de conteúdos relacionados à TRG, e um primeiro passo nesse sentido seria certamente discutir mais o assunto dentro dos espaços acadêmicos e divulgar amplamente os resultados de tais discussões na grande mídia, de modo a popularizar o debate curricular em nossa sociedade, preferencialmente numa perspectiva holística e interdisciplinar, capaz de modernizar o currículo atendendo às demandas de todas as áreas afins à FMC.

Uma idealização possível do currículo escolar, a ser almejada, nos permite compará-lo a um cardápio de restaurante onde todas as opções de alimento são nutritivas, com uma notável diferença com relação àquilo que observamos em nossas escolas: o cardápio sempre se encontra aberto à escolha das pessoas que vão consumir. Outro aspecto a contrapor, é que os cardápios não são uniformes, isto é, eles variam de um estabelecimento a outro oferecendo um leque de opções aos clientes, o que não ocorre com o currículo escolar! Os currículos das escolas são geralmente uniformes (com os mesmos conteúdos descritos e ensinados em todos os estabelecimentos), não restando aos estudantes outra escolha senão limitar-se a aprender conteúdos que, às vezes, são insuficientes para explicar suas experiências e realidades e, por isso, não correspondem às suas necessidades, expectativas e desejos. Nesse sentido, cabe propor a adoção de disciplinas eletivas no Ensino Médio, capazes de permitir aos alunos uma formação mais flexível e espontânea.

Muito ainda deve ser feito no sentido de superar a forma atual como os livros didáticos são estruturados, com os conteúdos de FMC situados exclusivamente no último capítulo que, segundo a fala de uma professora, é "aquele que nunca dá tempo ver" (OLIVEIRA; ALMEIDA, 2013, p. 112).

$\mathrm{O}$ ato de vincular os temas uso do cinto de segurança e do Princípio de Equivalência pode favorecer um ensino problematizado, uma vez que se aplicam conhecimentos científicos nas investigações reais vivenciadas pelos sujeitos, à medida que se aproximam as temáticas Educação no Trânsito e Ensino de Relatividade Geral, algo incomum até então. Vista de outra forma, esse tipo de abordagem possibilita que o aluno perceba a importância do referencial no estudo da Física, uma vez que, ao mudar de referencial, a explicação para o fenômeno 
em questão exigiu uma nova lei física.

O professor pode ainda usar essa discussão para apresentar aos seus alunos o primeiro postulado de Einstein da TRR, o Princípio da Relatividade, segundo o qual todas as leis físicas devem ser igualmente válidas em todos os referenciais inerciais, destacando que o fato de o observador em movimento não poder aplicar a Lei da Inércia para justificar o uso do cinto de segurança deve-se ao seu referencial, que não é inercial. Outras estratégias devem ser pensadas de forma a viabilizar abordagens mais lúdicas, contextualizadas e interdisciplinares de tópicos de Física, em especial os de FMC cujas abordagens são menos frequentes.

\section{REFERÊNCIAS}

ARINGHIERI, L. F.; SILVA, F. A. Teatro de fantoches: Uma apresentação lúdica de física moderna em escolas do ensino fundamental. Scientia Plena, v. 13, n. 1, p. 1-10, 2017.

BRASIL. Código de Trânsito Brasileiro. Lei n 9.503, de 23 de setembro de 1997. Instituiu o Código de Trânsito Brasileiro. República Federativa do Brasil. 1997. Disponível em: <http: //www.planalto.gov.br/ccivil_03/leis/19503.htm> Acesso em: 25 abr. 2019.

FERREIRA, R. d. C.; SILVA, M. d. F. A. d. Uma proposta para a introdução da relatividade geral no ensino médio. In: XVII Simpósio Nacional de Ensino de Física. São Luís: Sociedade Brasileira de Física, 2007. v. 1, p. 1-11.

GUERRA, A.; BRAGA, M.; REIS, J. C. Teoria da relatividade restrita e geral no programa de mecânica do ensino médio: uma possível abordagem. Revista Brasileira de Ensino de Física, v. 29, n. 4, p. 575-583, 2007.

MEDEIROS, A.; MEDEIROS, C. F. de. Einstein, a física dos brinquedos e o princípio da equivalência. Caderno Brasileiro de Ensino de Física, Universidade Federal de Santa Catarina (UFSC), v. 22, n. 3, p. 299-315, 2005.

MOREIRA, M. C. d. A.; PEREIRA, M. V.; MARTINS, I. G. Mecânica e educação para o trânsito: análise de um texto didático de ciências para o ensino fundamental. Revista Brasileira de Ensino de Física, SciELO Brasil, v. 39, n. 4, p. 1-7, 2017.

OLIVEIRA, A. N. d.; ALMEIDA, C. A. S. d. Ensino de relatividade especial no ensino médio: uma abordagem progressiva. In: LIMA, I. B. (Ed.). Didática, Educação Ambiental e Ensino de Ciências e Matemática: múltiplos olhares, II: didática e ensino de ciências e matemática. Fortaleza: UECE, 2013. p. 107-117.

OSTERMANN, F.; MOREIRA, M. A. Uma revisão bibliográfica sobre a área de pesquisa "física moderna e contemporânea no ensino médio”. Investigações em ensino de ciências, v. 5, n. 1, p. 23-48, 2000.

RODRÍGUEZ, G. C.; REYES, J. D.; ORTIZ, E. El principio de equivalencia: una propuesta didáctica a partir del juguete de einstein. Latin-american Journal of Physics Education, Instituto Politécnico Nacional, v. 8 , n. 4 , p. $1-5,2014$

SILVA, J. R. N.; ARENGHI, L. E. B.; LINO, A. Porque inserir física moderna e contemporânea no ensino médio? uma revisão das justificativas dos trabalhos acadêmicos. Revista Brasileira de Ensino de Ciência e Tecnologia, v. 6, n. 1, p. 16-22, 2013.

TERRAZZAN, E. A. A inserção da física moderna e contemporânea no ensino de física na escola de $2^{\circ}$ grau. Caderno Brasileiro de Ensino de Física, Universidade Federal de Santa Catarina (UFSC), v. 9. n. 3, p. 209-214, 1992. 